\title{
OPEN Desulfurization of liquid fuels using aluminum modified mesoporous adsorbent: towards experimental and kinetic investigations
}

\author{
Mohammad Reza Khosravi-Nikou ${ }^{1 凶}$, Mohammad Hadi Safari ${ }^{1}$, Amir Asadi Rad $^{1}$, \\ Pouya Hassani ${ }^{1}$, Mohammad Mohammadian ${ }^{1}$, Maryam Ahmadi ${ }^{2}$, Negin Ghafari ${ }^{1}$ \& \\ Maryam Naseri ${ }^{3 凶}$
}

In this study, a modified mesoporous adsorbent (MSU-S) impregnated by aluminum was used to remove the aromatic sulfur compounds from $n$-decane as the model fuel. Physical and chemical properties of as-synthesized adsorbent were investigated by XRD (X-Ray Diffraction), SEM (Scanning Electron Microscopy), FTIR (Fourier Transform Infrared spectroscopy) and BET (Brunauer-EmmettTeller) method. Adsorptive desulfurization of model fuel was studied through batch and continues processes under mild temperature and normal atmospheric pressure. The equilibrium adsorption was modeled by Langmuir, Temkin, and Freundlich and the kinetics of adsorption was studied through first, second and intraparticle diffusion models. It was figured out that Temkin and the pseudo-secondorder model were best fitting the adsorption equilibrium and describing the kinetics, respectively.

Sulfur combinations present in fuel lead to sulfur dioxide and sulfate particulate generation and they are a major source of environmental pollutions ${ }^{1,2}$. When reduction of $\mathrm{CO}$ and $\mathrm{NO}_{\mathrm{x}}$ are intended in the automobile catalytic guards, organic sulfur compounds can reduce efficiently by poisoning of the catalysts ${ }^{3,4}$. Therefore, fuel desulfurization is one of the most important research areas to overcome this negative effect.

The main sulfur containing compounds (SCCs) in the liquid fossil fuels are thiophene (T) and its derived compounds such as, benzothiophene (BT), dibenzothiophene (DBT) and 4,6- dimethyldibenzothiophene $(4,6-$ $\mathrm{DMDBT}$ ). There are also some other low molecular weight compounds such as $\mathrm{SO}_{2}, \mathrm{SO}_{3}, \mathrm{H}_{2} \mathrm{~S}$ which are produced during the combustion and degradation process ${ }^{5,6}$.

To reach the acceptable level of SCCs in the fuel, petroleum refineries use hydrodesulfurization technology (HDS) to reduce sulfur content of hydrocarbon products. But this technic is not ecconomic and effective for sulfur compounds removal because it needs high temperature and pressure and therefore, high operational $\operatorname{costs}^{1-3,7-10}$. In order to overcome these difficulties for production of the ultra-clean fuel, alternative methods are investigated. Among of these emerging technologies, adsorptive desulfurization is an alternative to the HDS due to its mild operating conditions. In this process, the removal efficiency can be varied by the physico-chemical properties of adsorbents ${ }^{11}$. For this purpose, different classes of the adsorbents such as reduced metals ${ }^{12}$, metal oxides $^{13}$, metal organic frameworks ${ }^{14}$, zeolite-based materials ${ }^{15}$, carbon or carbon-based composite materials are investigated. Until now, zeolite-based compounds named MSU-S are considered significantly because of their available wide sources, low costs, high surface area and ease of modification in structure ${ }^{16-19}$.

One of the main disadvantages of MSU-S mesoporous materials is the low selectivity towards SCCs. In other words, MSU-S adsorption capability of SCCs and other competitive components in the fuel is almost the same. Therefore, developing highly selective MSU-S with enough loading capacity is important to enhance the adsorption of sulfur compounds in the fuel. In the previous work, different modifications like $\mathrm{CeO}_{2}-\mathrm{MSU}-\mathrm{S}$, $\mathrm{Cu}_{2} \mathrm{O}-\mathrm{MSU}-\mathrm{S}, \mathrm{CoO}_{2}$-MSU-S, $\mathrm{Fe}_{2} \mathrm{O}_{3}$-MSU-S and $\mathrm{CrO}_{2}$-MSU-S are introduced and it was obtained that modification by copper has the best performance among other metals to remove sulfur containing compounds $\mathrm{s}^{3,20,21}$.

The main goal of this work was to remove sulfur components in the synthetized fuel using $\mathrm{Al}_{2} \mathrm{O}_{3}$-MSU-S. The properties of as-synthesized sorbent was examined by BET, XRD, FESEM and FT-IR techniques. Batch

\footnotetext{
${ }^{1}$ Department of Gas Engineering, Ahwaz Faculty of Petroleum, Petroleum University of Technology, Ahwaz, Iran. ${ }^{2}$ Department of Chemical Engineering, Abadan Faculty of Petroleum, Petroleum University of Technology, Abadan, Iran. ${ }^{3}$ Department of Chemical Engineering, Faculty of Engineering, Golestan University, Aliabad Katoul, Iran. ${ }^{\boxplus}$ email: khosravi_m@yahoo.com; naaseri1375@gmail.com
} 
and continuous adsorption tests were performed and the adsorption was investigated thermodynamically and kinetically.

\section{Experimental}

Chemicals. Sodium aluminate and fumed silica were prepared from Sigma-Aldrich Chemical Co. (USA). $\mathrm{N}$-decane, tetrapropylammonium hydroxide (TPAOH $40 \%$ aqueous solution), dibenzothiophene, hexa decyl trimethylammonium bromide (HTABr) of synthetic grade, ethanol $(>99 \%)$, nonahydrated aluminum nitrate of analytical grade were bought from Merck Co. These compounds were employed without any purifying process.

Preparation of material. MSU-S. The methodology used to synthesize MSU-S (MFI) mesoporous adsorbent was like what is explained by Rashidi et al. ${ }^{21} .79 .26 \mathrm{~g}$ of deionized water was blended with $10.2 \mathrm{~g}$ of TP$\mathrm{AOH}$ for MFI formation resource. After that sodium aluminate $(0.34 \mathrm{~g})$ and fumed silica $(6.0 \mathrm{~g})$ were blended in the TPAOH. Then it was blended in an Erlenmeyer flask (braced completely to inhibit water vaporization while aging and to hold the chemicals composition ratio constant) for $18 \mathrm{~h}$ at the water bath of $50^{\circ} \mathrm{C}$ to obtaining zeolite MFI grains. So, HTABr $(9.44 \mathrm{~g})$ as the surfactant was blended with deionized water (100 g) and added to the suspension of grains to make the mesoporous structure. Afterward, sulfuric acid $(0.1 \mathrm{M})$ was injected to the chemicals to retain $\mathrm{pH}$ at 9 . The produced gel was placed in the stainless-steel autoclave, then kept in the oven at $150{ }^{\circ} \mathrm{C}$ for $48 \mathrm{~h}$. The produced powder was washed several times using DW and then filtered and placed at $80^{\circ} \mathrm{C}$ oven for $9 \mathrm{~h}$. After that, the white chemical was introduced to the mixture of $0.1 \mathrm{M} \mathrm{NH}_{4} \mathrm{NO}_{3}$ and ethanol with a reflux temperature for ion exchanging. The resulting material was desiccated at $90^{\circ} \mathrm{C}$ for $12 \mathrm{~h}$. The final product was calcinated in the muffle furnace at $550{ }^{\circ} \mathrm{C}$ in the air at $1{ }^{\circ} \mathrm{C} / \mathrm{min}$ for $10 \mathrm{~h}$.

Impregnation. $\mathrm{Al}\left(\mathrm{NO}_{3}\right)_{3}$ used as an aluminum source to be loaded on MSU-S. In order to make a dispersed phase of $\mathrm{Al}_{2} \mathrm{O}_{3}$ on the MSU-S, the required amount of metal precursor was mixed in DW. A specific amount of MSU-S was introduced to the mixture while it was mixed and left over the night at $70{ }^{\circ} \mathrm{C}$ to lose moisture. The prepared gel was desiccated at $90^{\circ} \mathrm{C}$ for $12 \mathrm{~h}$. After that, for the calcination process, the final product was put in the furnace and heated with the rate of $1{ }^{\circ} \mathrm{C} / \mathrm{min}$ to reach $550{ }^{\circ} \mathrm{C}$ and preserved at this temperature for $4 \mathrm{~h}$. In order to activate the synthesized material and before being used in the adsorption test, it was placed at hydrogen atmosphere at $190^{\circ} \mathrm{C}$.

Model fuel. To prepare synthesized fuel like a real fuel, $n$-decane as the paraffinic compound and dibenzothiophene as the sulfur source were used.

Characterization of samples. The XRD (X-ray diffraction) was studied applying wave length $=1.5418 \AA$, $40 \mathrm{kV}$ and $40 \mathrm{~mA}$ of $\mathrm{Cu} \mathrm{Ka}$ radiation in the domain from $1^{\circ}$ to $10^{\circ}$ and $20^{\circ}$ to $80^{\circ}$. The Fourier transform infrared (FTIR) pattern of the adsorbent was reported on the Nicolet Impact 400.128 scans were picked at a $4 \mathrm{~cm}^{-1}$ resolution in the mid-IR region using $\mathrm{KBr}$. The Brunauer-Emmett-Teller (BET) was applied to derive surface area and average pore diameter. The textural properties of the materials were investigated by $\mathrm{N}_{2}$ adsorption/ desorption at $-196^{\circ} \mathrm{C}$ with the Belsorp-mini-instrument. SEM (scanning electron microscopy) was done on the Zeiss instrument for the morphological study of the sorbent. The chemical analysis of Energy dispersive X-ray spectroscopy (EDS) was performed with Oxford Instrument.

General adsorption tests. Batch process. Batch experiment is done to discuss equilibrium and kinetics of adsorption of DBT on $\mathrm{Al}_{2} \mathrm{O}_{3}$-MSU-S and then to investigate adsorption capacity, equilibrium and kinetics models. For all experiments, $0.2 \mathrm{~g}$ adsorbent and $0.5 \mathrm{~g}$ model fuel were used. The tests were performed in the capped vials and mixed with constant stirring speed of $250 \mathrm{rpm}$ at room temperature and atmospheric conditions.

Continuous adsorption experimental procedure. In order to get the breakthrough and saturation amount for the adsorbent, the experiments were performed in a continuous process. For the continuous tests, DBT content in the fuel was considered to be $400 \mathrm{ppmw}$. The breakthrough /adsorption experiments were done in the reactor of fixed-bed stainless-steel ( $150 \mathrm{~mm}$ long, $10 \mathrm{~mm}$ internal diameter) with a layer of quartz sand. Approximately, $0.5 \mathrm{~g}$ of $\mathrm{Al}_{2} \mathrm{O}_{3}$-MSU-S was placed into the reactor. In order to obtain the saturation point the treated fuel was sampled every 5-10 min.

Sulfur concentration analysis. The sulfur amount in the synthesized fuel was defined by GC Gas Chromatograph YL6100 model with the capillary column (5 TRB, Length: $30 \mathrm{~m}$, Internal Diameter: $0.32 \mathrm{~mm}$, DF: $1 \mu \mathrm{m}$; Teknokroma.), and the FID containing He as carrier gas.

\section{Results and discussion}

Adsorbent features. XRD. Figure la shows the XRD low-angle spectra of the adsorbents. As it illustrate, the influence of loading aluminum decreases maximum intensity of MSU-S clearly, which depicts that crystalline phase converts to amorphous phase relatively ${ }^{24-26}$. It is obvious that impregnating of aluminum has a negative impact on mesoporous pattern of MSU-S. As illustrated in Fig. 1b, there are four maximums in the highangle area of XRD spectra of $\mathrm{Al}_{2} \mathrm{O}_{3}$-MSU-S, associated with the head for MSU-S hexagonal mesostructure. All these maximum points indicate the formation of crystalline phase of aluminum oxide on the adsorbent (MSU-S) after being injected on the surface ${ }^{6}$ (Fig. 2). 


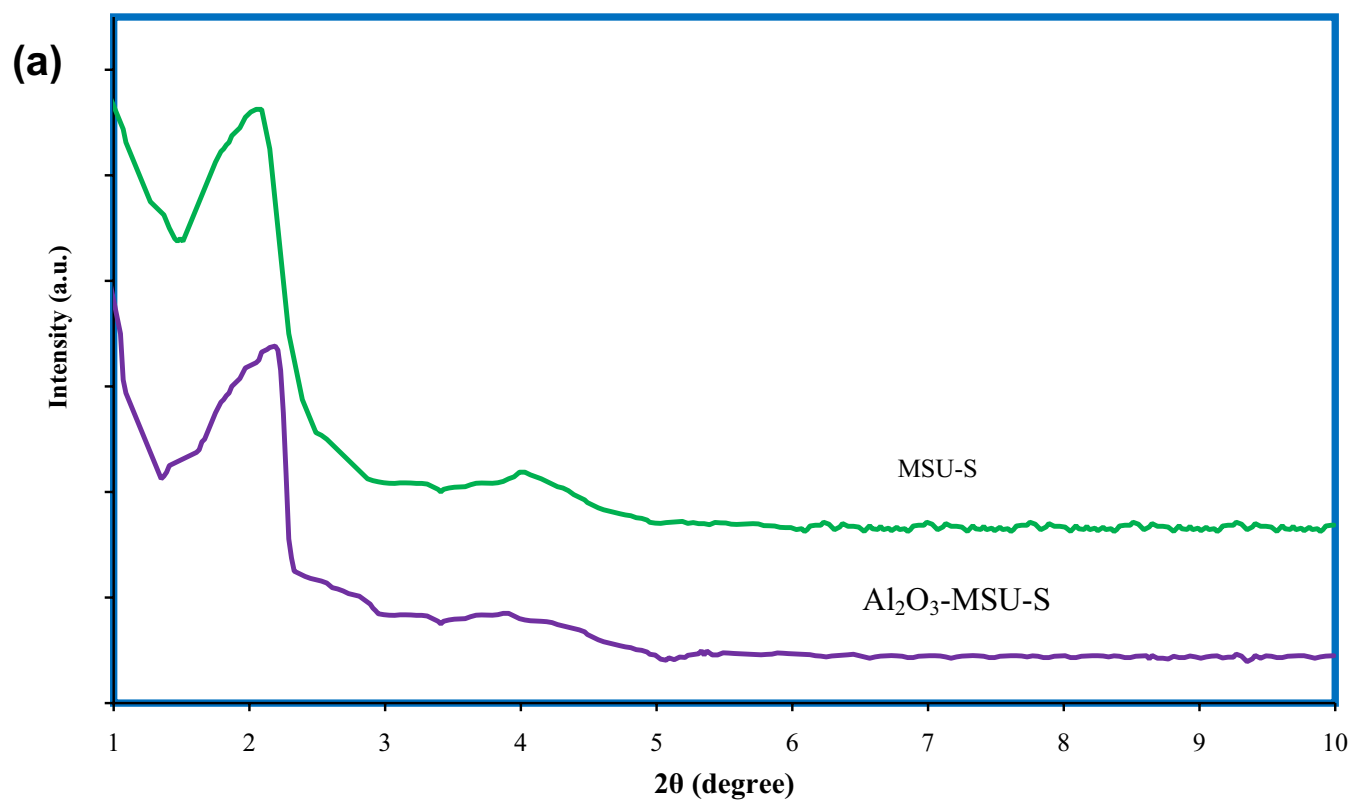

(b)

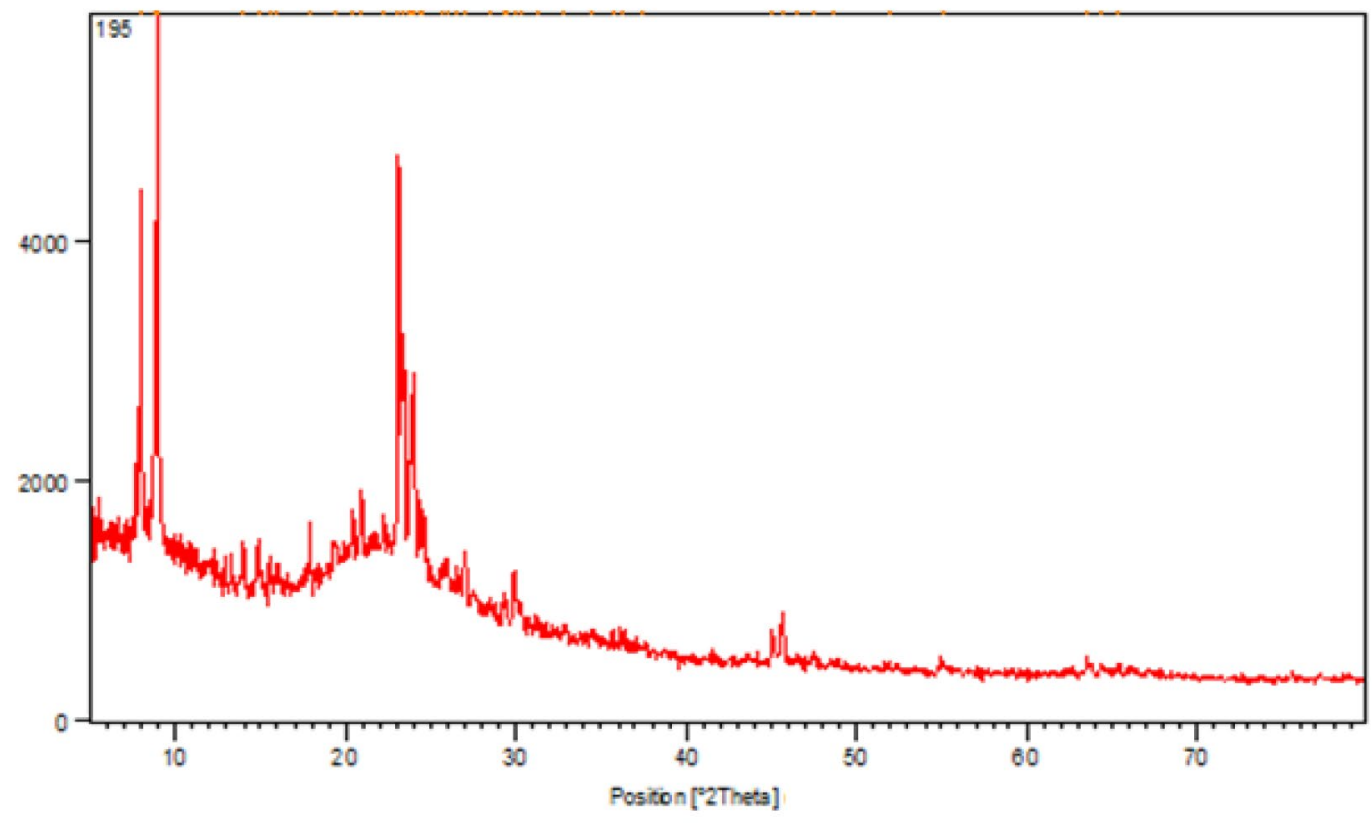

Figure 1. (a) XRD with Small-angle pattern for MSU-S and $\mathrm{Al}_{2} \mathrm{O}_{3}-\mathrm{MSU}-\mathrm{S}$ (b) XRD with wide-angle pattern of $\mathrm{Al}_{2} \mathrm{O}_{3}$-MSU-S.

Nitrogen adsorption-desorption. Volume, mean diameter of the pores and BET surface area for MSU-S and $\mathrm{Al}_{2} \mathrm{O}_{3}$-MSU-S are presented in Table 1. It shows that the surface area of MSU-S was decreased when impregnated by aluminium. Nitrogen adsorption-desorption isotherm is demonstrated in Fig. 3. It is obvious that there is a hysteresis loop during adsorption-desorption. According to the IUPAC classification, isotherm type IV can be used to describe hysteresis behavior of $\mathrm{Al}_{2} \mathrm{O}_{3}$-MSU-S that is the characteristic feature of mesoporous solid. A low-pressure hysteresis which is gained in Fig. 3 extending to the lowest achievable pressures. A step occurs in the adsorption curve between partial pressures $\mathrm{P} / \mathrm{Po}$ of 0.8 to 1 . Figure 4 illustrates the pore size dispensation of $\mathrm{Al}_{2} \mathrm{O}_{3}$-MSU-S. The sharp peak around $21 \AA$ in this figure might be according to the internal cavity and represents the narrow pore size $\mathrm{s}^{28-33}$.

Fourier transform infrared (FTIR) pattern. The FTIR pattern of MSU-S and $\mathrm{Al}_{2} \mathrm{O}_{3}-\mathrm{MSU}-\mathrm{S}$ is presented in Fig. 2. It indicates that $\mathrm{Si}-\mathrm{O}-\mathrm{Si}$ bond is asymmetric internally and stretches at 1103 per cm. The Si-O-Si pro- 

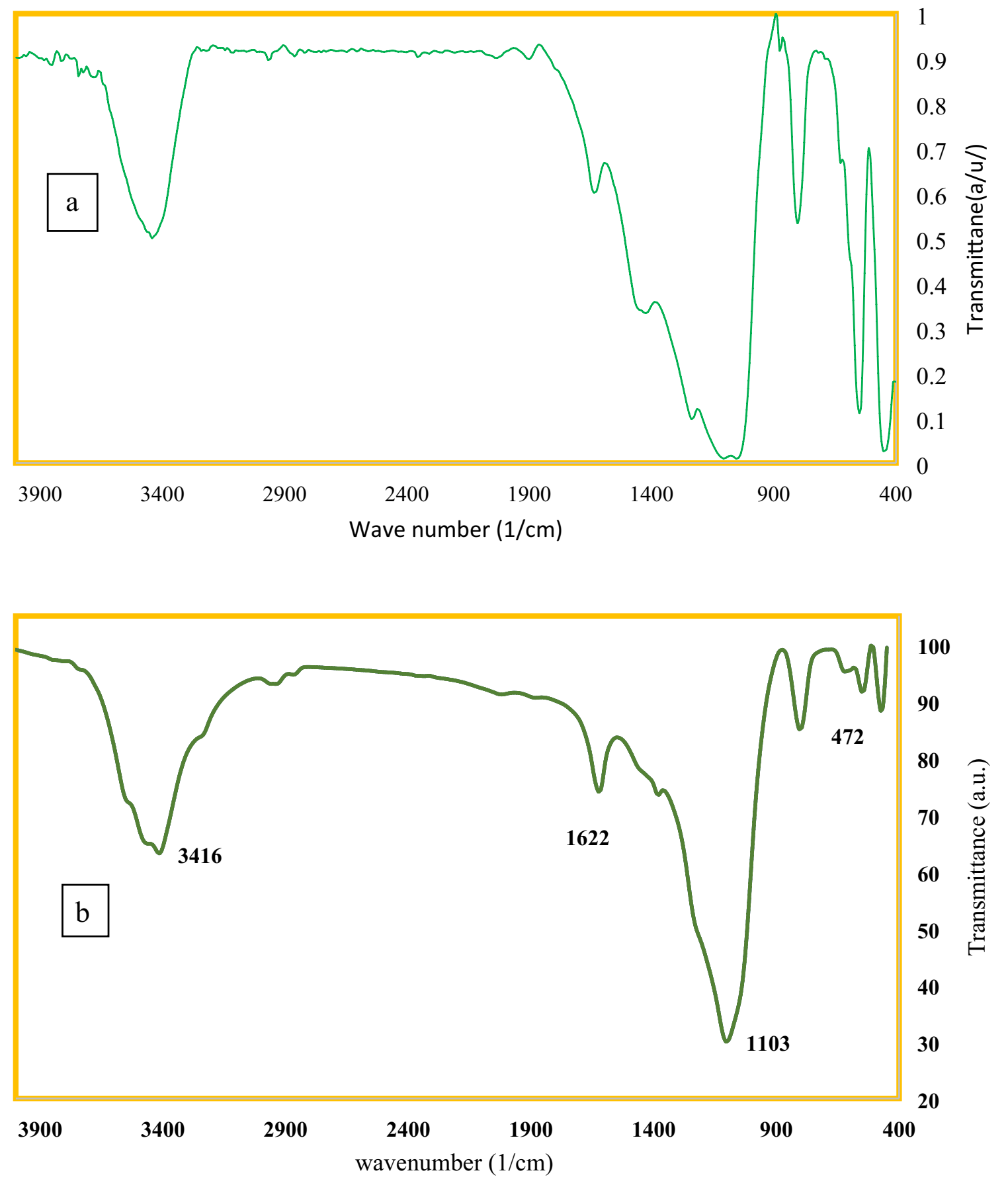

Figure 2. FTIR spectra of two adsorbents. (a) MSU-S and (b) $\mathrm{Al}_{2} \mathrm{O}_{3}-\mathrm{MSU}-\mathrm{S}$.

\begin{tabular}{|l|l|l|l|}
\hline Sorbent & BET surface area $\left(\mathbf{m}^{2} / \mathbf{g}\right)$ & Mean pore diameter $(\AA)$ & Total pore volume $\left(\mathbf{c m}^{3} / \mathbf{g}\right)$ \\
\hline MSU-S & 677 & 24 & 0.65 \\
\hline $\mathrm{Al}_{2} \mathrm{O}_{3}$-MSU-S & 158 & 21 & 0.60 \\
\hline
\end{tabular}

Table 1. Textural features of the sorbents.

portioned length exists at 472 per $\mathrm{cm}$ is related to the $\mathrm{Si}-\mathrm{O}-\mathrm{Al}$ in the adsorbent. The band at 3416 per $\mathrm{cm}$ related to the silanol group that is the characteristic of adsorbent. The different band that appears in this adsorbent in comparison with spectrum of MSU-S, centered at $1622 \mathrm{~cm}^{-1}$. So, it is concluded that nitrate of the metal reacted with the empty places Al2O3-MSU-S $20,27,28$. 


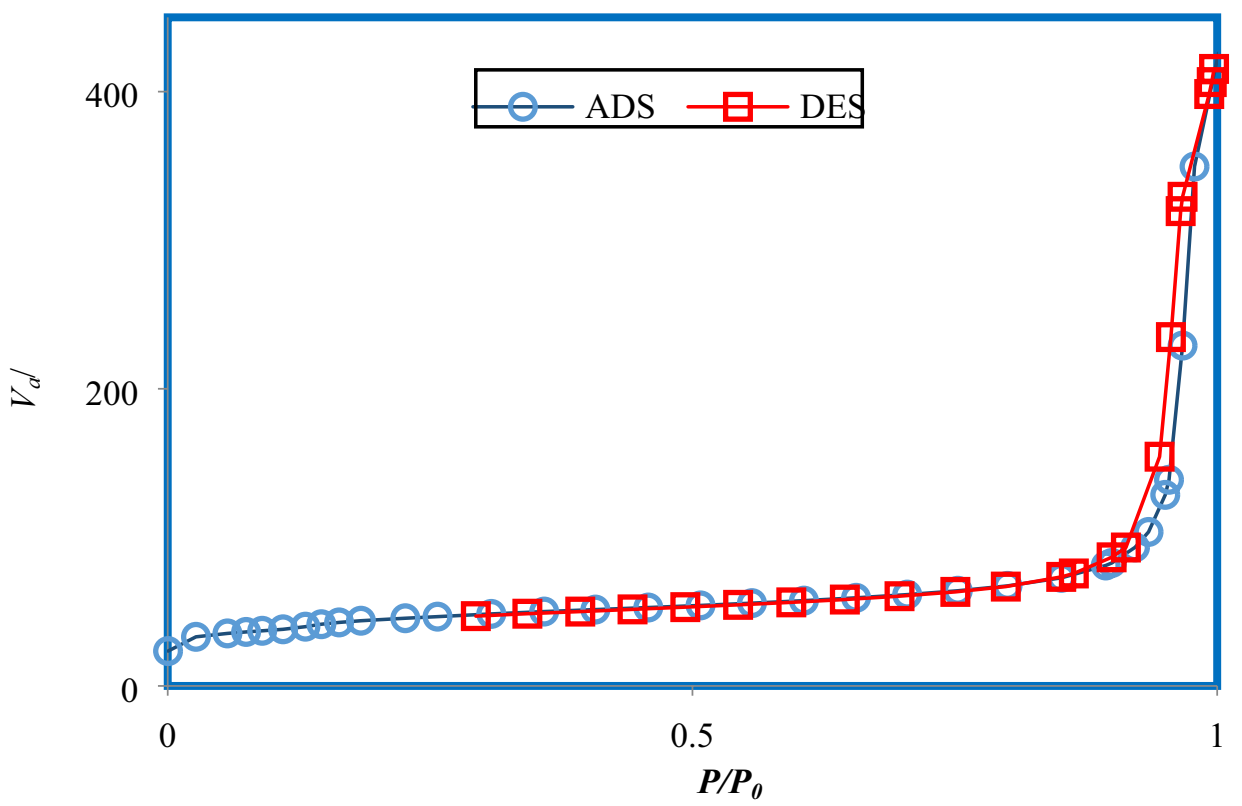

Figure 3. Nitrogen adsorption-desorption isotherm for $\mathrm{Al}_{2} \mathrm{O}_{3}-\mathrm{MSU}-\mathrm{S}$.

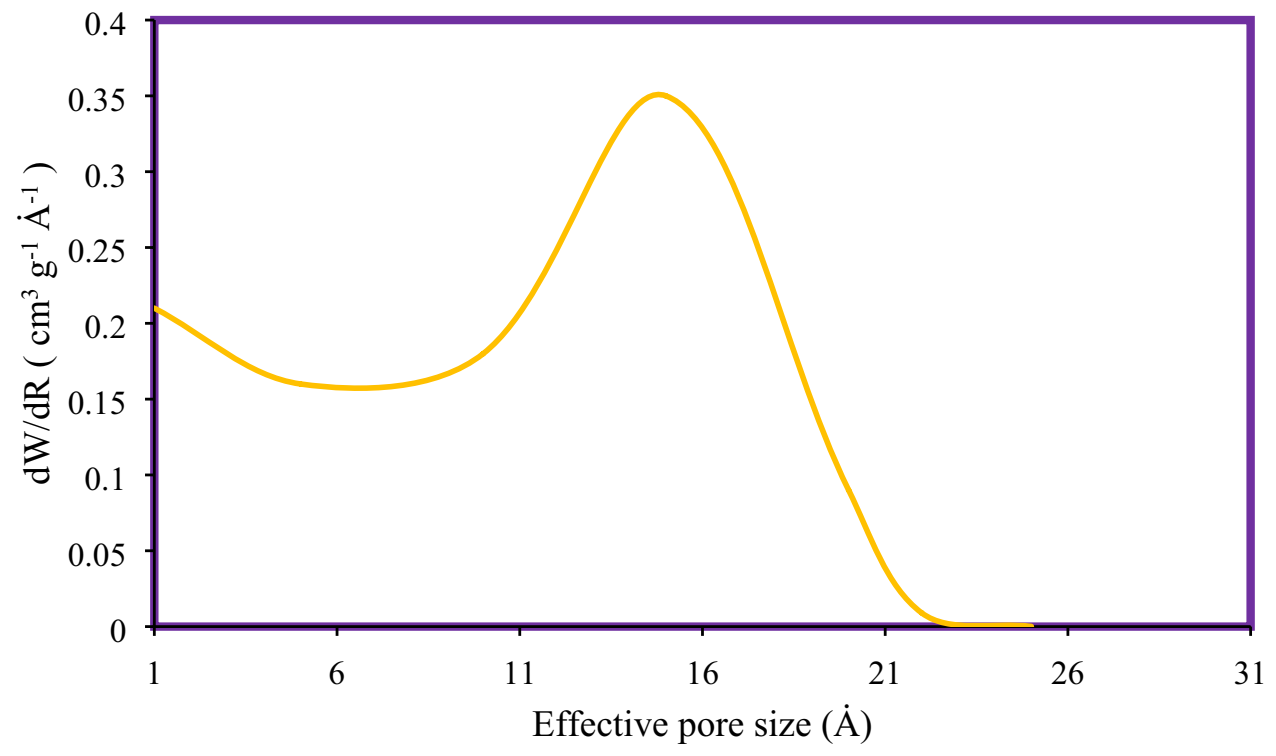

Figure 4. Pore size distribution for $\mathrm{Al}_{2} \mathrm{O}_{3}$-MSU-S.

FESEM image and EDS result. SEM image and EDS of the sample are illustrated in Fig. 5. $\mathrm{The} \mathrm{Al}_{2} \mathrm{O}_{3}$-MSU-S sample shows aggregates of rounded particle ${ }^{3}$. The EDS results in the images verifies successfully loading of $\mathrm{Al}_{2} \mathrm{O}_{3}$ on the surface of adsorbent.

Adsorption mechanism. As mentioned in other studies and research, sulfur compounds can be removed by certain sorbents either through the $\mathrm{S}-\mathrm{M}$ bonds formation or the $\pi$-complexation. Direct sulfur-sorbent interactions by ion exchange between metal oxide $\left(\mathrm{Al}^{3+}\right)$ and sulfur compounds can be attributed to hard and soft acids and bases (HSAB) principle. According to this theory, hard acids prefer to connect with hard bases, and soft acids prefer soft bases. The large differences in electronegativity between hard acids and hard bases leads to strong ionic interactions. The electronegativities of soft acids and soft bases are almost the same and therefore, they have less ionic interactions and they almost make covalent connections. The interactions between hard acid-soft base or soft acid-hard base are mostly polar covalent and tend to be more reactive or less stable. The polar covalent compounds readily make either ionic or covalent compounds if they are permitted to react. $\mathrm{Al}^{3+}$ is a hard acid and prefers to combine with DBT by the direct S-M (metal oxide) $\sigma$-bond. In this case, the strength of the direct S-M $\sigma$-bond basically depends on the charge number and ionic radius of the metal ion ${ }^{21}$. 

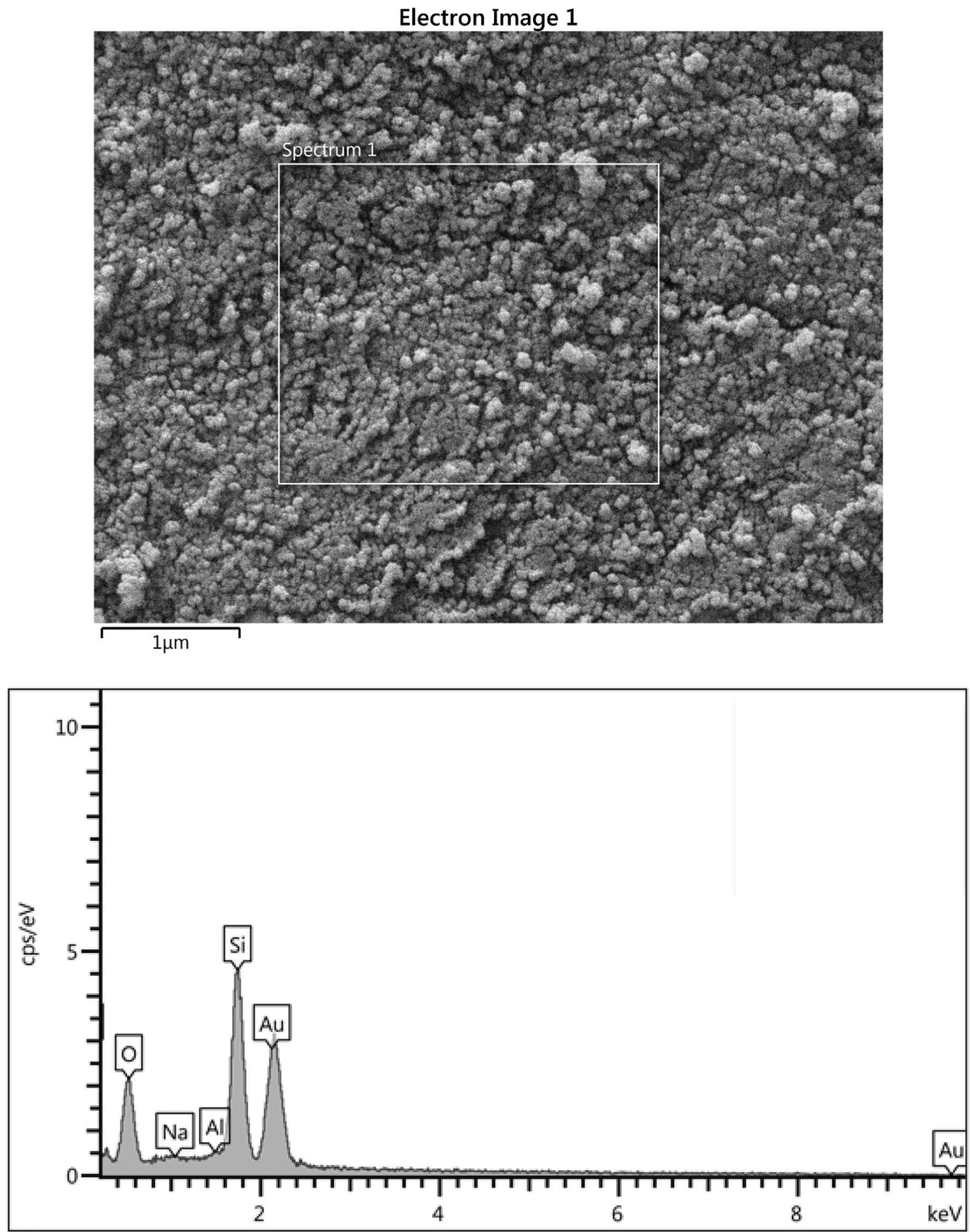

Figure 5. SEM scans and EDS analysis of $\mathrm{Al}_{2} \mathrm{O}_{3}-\mathrm{MSU}-\mathrm{S}$.

Adsorption equilibrium. Synthetic fuel with various amounts of DBT was applied to investigate the adsorption isotherms. The Freundlich, Temkin and Langmuir isotherms were applied to examine equilibrium results. Equations (1)-(3) show the mathematical form of the isotherms:

$$
\text { Langmuir isotherm : } q_{e}=\frac{q_{m} K_{L} C_{e}}{1+K_{L} C_{e}}
$$

$$
\text { Freundlich isotherm }: q_{e}=K_{F} C_{e}^{\frac{1}{n}}
$$




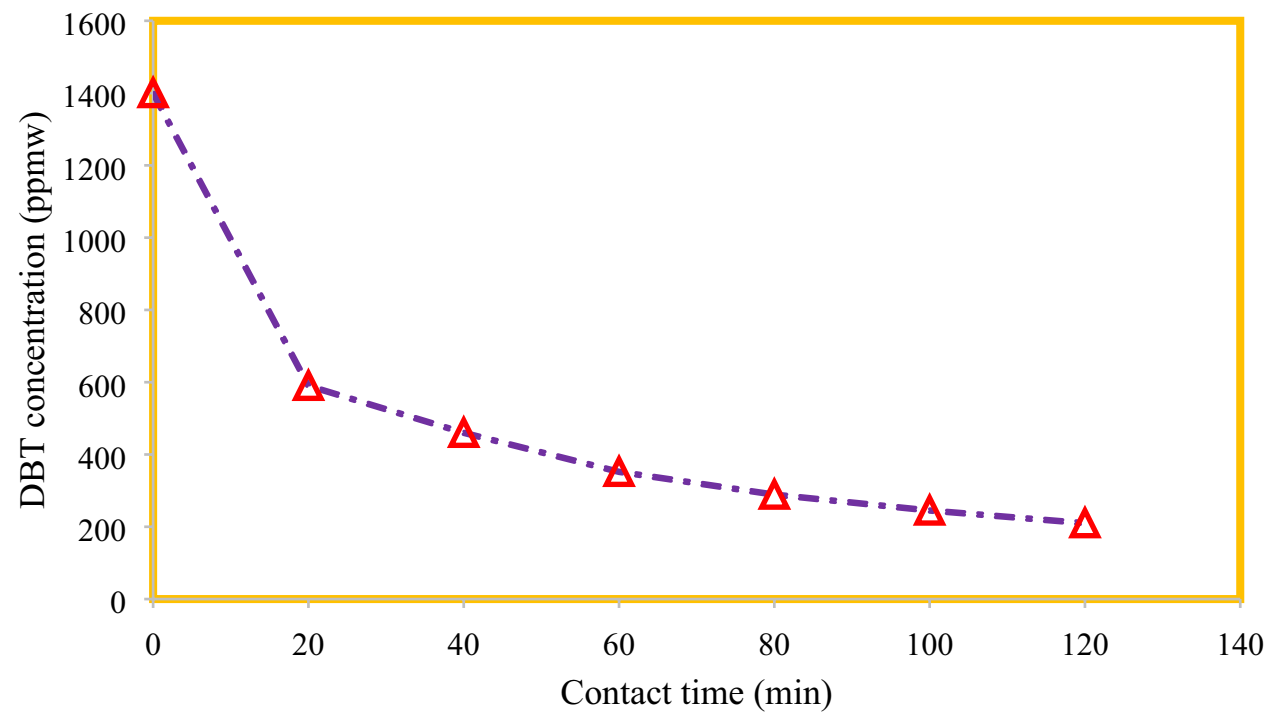

Figure 6. Contact time effect on $\mathrm{Al}_{2} \mathrm{O}_{3}$-MSU-S execution.

$$
\text { Temkin isotherm : } q_{e}=\frac{R T}{b_{T}} \ln A_{T} C_{e}
$$

$C_{e}\left(\mathrm{mg} \mathrm{kg}^{-1}\right)$ is the content of sulfur-component material at equilibrium; $K_{L}\left(\mathrm{~kg} \mathrm{mg}^{-1}\right)$ and $q_{m}\left(\mathrm{mg} \mathrm{g}^{-1}\right)$ are the Langmuir isotherm parameters relevant to the adsorption energy and the largest load, respectively; $K_{F}\left(\mathrm{mg}^{1-(1 / \mathrm{n})}\right)$ $\mathrm{g}^{-1} \mathrm{~kg}^{1 / \mathrm{n}}$ ) and $1 / n$ show the Freundlich parameters relevant to the adsorption volume and also in Temkin ; $R$ is universal constant, $T$ is temperature, $A_{T}(\mathrm{~L} / \mathrm{g})$, and $b_{T}$ are Temkin constants, respectively; and $q_{e}\left(\mathrm{mg} \mathrm{g}^{-1}\right)$ is the content of sulfur-component adsorbed at the equilibrium/mass of adsorbent. Equations (4)-(6) show the linearized form of the Langmuir, Freundlich and Temkin models.

$$
\begin{aligned}
& \text { Langmuir isotherm : } \frac{1}{q_{e}}=\frac{1}{q_{m}}+\left(\frac{1}{K_{L} q_{m}}\right) \frac{1}{C_{e}} \\
& \text { Freundlich isotherm: } \ln q_{e}=\ln K_{F}+\frac{1}{n} \ln C_{e} \\
& \text { Temkin isotherm : } q_{e}=\frac{R T}{b_{T}} \ln A_{T}+\frac{R T}{b_{T}} \ln C_{e}
\end{aligned}
$$

$K_{L}$ and $q_{m}$ for Eq. (4), also $K_{F}$ and $1 / \mathrm{n}$ in Eq. (5), $\frac{R T}{b_{T}}$ and $A_{T}$ for Eq. (6) can be found using slope and intercept of the plotted experimental data. Figures $6,7,8$ illustrate the linear form of models fitted on the experimental data $^{2,19}$.

Tables 2 and 3 demonstrates the calculated parameters from regression of data and with the correspondence coefficient $\left(R^{2}\right)$ amounts of the models for adsorption isotherms for MSU-S and $\mathrm{Al}_{2} \mathrm{O}_{3}-\mathrm{MSU}-\mathrm{S}$. It is obvious that Temkin model can be used to define the adsorption of DBT on the sorbent due to higher values of $R^{2}$ compared with other models. Based on this model, there is an indirect adsorption interaction between DBT and $\mathrm{Al}_{2} \mathrm{O}_{3}$-MSU-S as adsorbent. It means the heat of adsorption decreases with increasing coverage in a linear relation. Therefore, a uniform distribution of binding energies was observed in the adsorption process.

Kinetics of DBT adsorption. From Fig. 6 it is clear that by increasing the contact time between model fuel and adsorbent, the residual concentration of sulfur content decreased. This figure points out that the major and effective adsorption takes place in the first $40 \mathrm{~min}$ and after a while reaches to an asymptotic amount.

Pseudo-first order, pseudo-second order, and intraparticle diffusion kinetic relations have been utilized to assess the kinetics of sulfur adsorption onto $\mathrm{Al}_{2} \mathrm{O}_{3}$-MSU-S.

The pseudo-first order relation is shown as:

$$
\frac{d q_{t}}{d t}=k_{\text {lad }}\left(q_{e}-q_{t}\right)
$$

$q_{t}=$ adsorption loads $(\mathrm{mg} / \mathrm{g})$ at the time of $t, q_{e}=$ adsorption loads $(\mathrm{mg} / \mathrm{g})$ at equilibrium, $k_{1 a d}=$ constant rate of pseudo-first order adsorption (per minute).

Integrating from Eq. (7) and employing boundary limits from $t=0$ to $t=t$ and $q_{t}=0$ to $q_{t}=q_{t}$, leads to the following equation: 


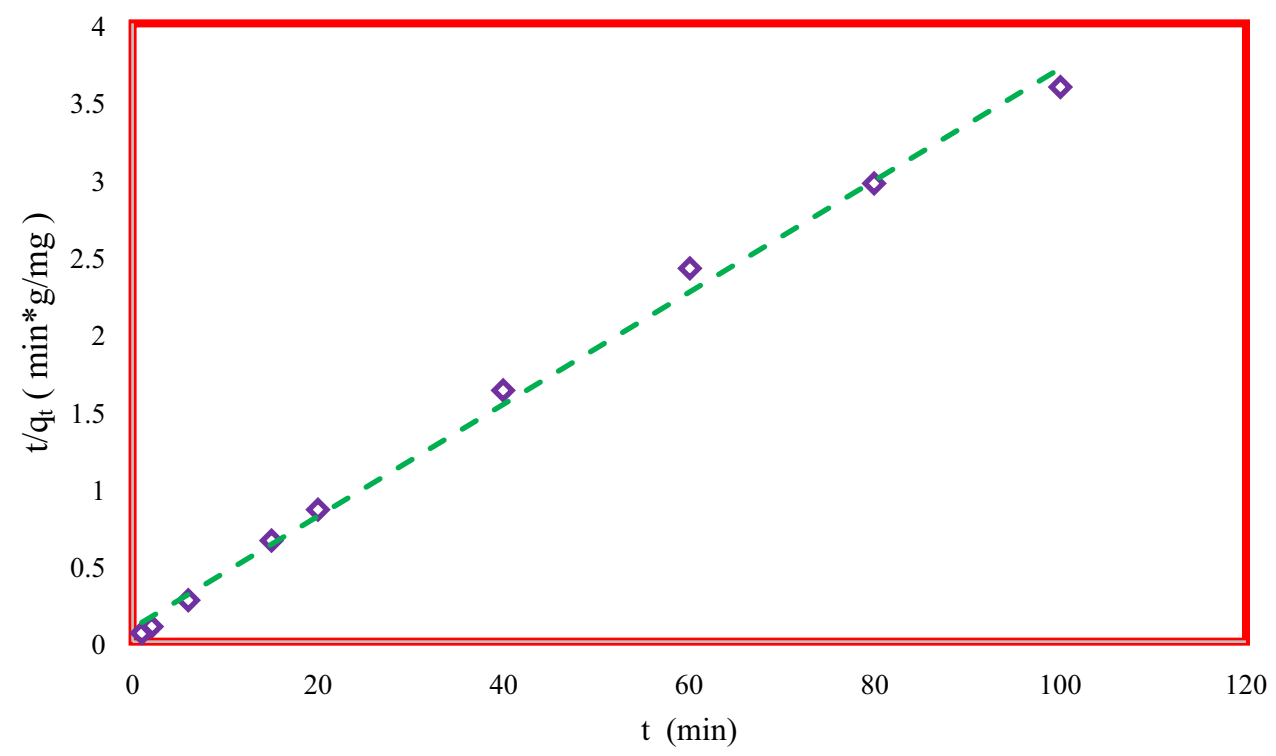

Figure 7. Pseudo-second order performance to predict experimental data.

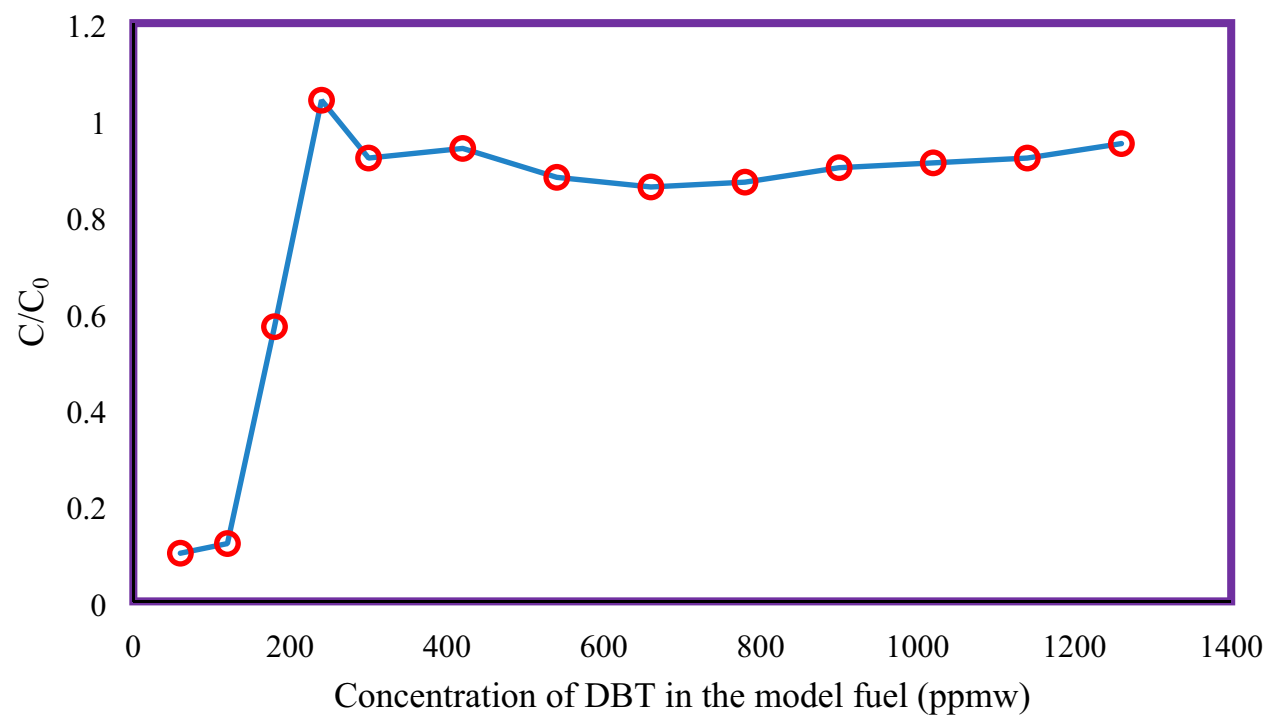

Figure 8. Breakthrough curves of adsorption of DBT on $\mathrm{Al}_{2} \mathrm{O}_{3}$-MSU-S $\left(1 \mathrm{~atm}, 25^{\circ} \mathrm{C}, 1.0186 \mathrm{~h}^{-1}\right)$.

\begin{tabular}{|l|l|l|}
\hline Isotherm model & Parameters & Compound (DBT) \\
\hline \multirow{4}{*}{ Langmuir } & $\mathrm{q}_{\mathrm{m}}(\mathrm{mg} / \mathrm{g})$ & 19.23 \\
\cline { 2 - 3 } & $\mathrm{K}_{\mathrm{L}}(\mathrm{kg} / \mathrm{mg})$ & 0.00226 \\
\cline { 2 - 3 } & $\mathrm{R}^{2}$ & 0.9955 \\
\hline \multirow{4}{*}{ Freundlich } & $1 / \mathrm{n}$ & 0.472 \\
\cline { 2 - 3 } & $\mathrm{K}_{\mathrm{F}}(\mathrm{mg} / \mathrm{g})(\mathrm{kg} / \mathrm{g})^{1 / \mathrm{n}}$ & 1.25 \\
\cline { 2 - 3 } Temkin & $\mathrm{R}^{2}$ & 0.9732 \\
\hline \multirow{3}{*}{} & $\mathrm{A}_{\mathrm{T}}(\mathrm{kg} / \mathrm{g})$ & 0.0184 \\
\cline { 2 - 3 } & $\mathrm{RT}^{2} \mathrm{~b}_{\mathrm{T}}$ & 4.61 \\
\cline { 2 - 3 } & $\mathrm{R}^{2}$ & 0.9963 \\
\hline
\end{tabular}

Table 2. Different isotherm models for DBT adsorption on MSU-S. 


\begin{tabular}{|l|l|l|}
\hline Isotherm model & Parameters & Compound (DBT) \\
\hline \multirow{5}{*}{ Langmuir } & $\mathrm{q}_{\mathrm{m}}(\mathrm{mg} / \mathrm{g})$ & 66.67 \\
\cline { 2 - 3 } & $\mathrm{K}_{\mathrm{L}}(\mathrm{kg} / \mathrm{mg})$ & 0.00106 \\
\cline { 2 - 3 } & $\mathrm{R}^{2}$ & 0.8450 \\
\hline \multirow{5}{*}{ Freundlich } & $1 / \mathrm{n}$ & 0.437 \\
\cline { 2 - 3 } & $\mathrm{K}_{\mathrm{F}}(\mathrm{mg} / \mathrm{g})(\mathrm{kg} / \mathrm{g})^{1 / \mathrm{n}}$ & 1.65 \\
\cline { 2 - 3 } & $\mathrm{R}^{2}$ & 0.8990 \\
\hline \multirow{3}{*}{ Temkin } & $\mathrm{A}_{\mathrm{T}}(\mathrm{kg} / \mathrm{g})$ & 0.013 \\
\cline { 2 - 3 } & $\mathrm{RT} / \mathrm{b}_{\mathrm{T}}$ & 13.057 \\
\cline { 2 - 3 } & $\mathrm{R}^{2}$ & 0.9100 \\
\hline
\end{tabular}

Table 3. Different isotherm models for DBT adsorption on $\mathrm{Al}_{2} \mathrm{O}_{3}-\mathrm{MSU}-\mathrm{S}$.

\begin{tabular}{|l|l|l|l|l|l|l|l|l|l|l|}
\hline \multirow{2}{*}{ Compounds } & \multicolumn{4}{|l|}{ Pseudo first-order } & \multicolumn{3}{l|}{ Pseudo second-order } & \multicolumn{2}{l|}{ Intraparticle diffusion } \\
\cline { 2 - 10 } & $\mathbf{q}_{\mathbf{e}}(\mathbf{m g} / \mathbf{g})$ & $\mathbf{k}_{\text {lad }}(\mathbf{1} / \mathbf{m i n})$ & $\mathbf{R}^{\mathbf{2}}$ & $\mathbf{q}_{\mathbf{e}}(\mathbf{m g} / \mathbf{g})$ & $\mathbf{k}_{\text {2ad }}(\mathbf{g} / \mathbf{m g} \cdot \mathbf{m i n})$ & $\mathbf{R}^{\mathbf{2}}$ & $\mathbf{q}_{\mathbf{e}}(\mathbf{m g} / \mathbf{g})$ & $\mathbf{k}_{\mathbf{i}}\left(\mathbf{g} / \mathbf{m g} \cdot \mathbf{m i n}^{\mathbf{0 . 5}}\right)$ & $\mathbf{R}^{\mathbf{2}}$ \\
\hline DBT & 15.16 & 0.032 & 0.9659 & 15.92 & 0.00225 & 0.9813 & 1.453 & 1.026 & 0.8765 \\
\hline
\end{tabular}

Table 4. Kinetical study for adsorption of DBT on MSU-S.

\begin{tabular}{|l|l|l|l|l|l|l|l|l|l|l|}
\hline \multirow{2}{*}{ Compounds } & \multicolumn{4}{|l|}{ Pseudo first-order } & \multicolumn{2}{l|}{ Pseudo second-order } & \multicolumn{3}{l|}{ Intraparticle diffusion } \\
\cline { 2 - 10 } & $\mathbf{q}_{\mathbf{e}}(\mathbf{m g} / \mathbf{g})$ & $\mathbf{k}_{\text {lad }}(\mathbf{1} / \mathbf{m i n})$ & $\mathbf{R}^{\mathbf{2}}$ & $\mathbf{q}_{\mathbf{e}}(\mathbf{m g} / \mathbf{g})$ & $\mathbf{k}_{\text {2ad }}(\mathbf{g} / \mathbf{m g} \cdot \mathbf{m i n})$ & $\mathbf{R}^{\mathbf{2}}$ & $\mathbf{q}_{\mathbf{e}}(\mathbf{m g} / \mathbf{g})$ & $\mathbf{k}_{\mathbf{i}}\left(\mathbf{g} / \mathbf{m g} \cdot \mathbf{m i n}^{\mathbf{0 . 5}}\right)$ & $\mathbf{R}^{\mathbf{2}}$ \\
\hline DBT & 9.99 & 0.011 & 0.9095 & 11.40 & 0.213 & 0.9958 & 19.10 & 0.8681 & 0.9031 \\
\hline
\end{tabular}

Table 5. Kinetical study for adsorption of $\mathrm{DBT}$ on $\mathrm{Al}_{2} \mathrm{O}_{3}$-MSU-S.

$$
\ln \left(q_{e}-q_{t}\right)=\ln q_{e}-k_{\text {lad }} t
$$

As shown in Eq. (8) if $\ln \left(q_{e}-q_{t}\right)$ vs. time is plotted, $k_{1 a d}$ and $\ln q_{e}$ could be defined through slope and intercept of the model, respectively. Equation (9) shows the pseudo-second-order kinetic reltion ${ }^{34-36}$ :

$$
\frac{d q_{t}}{d t}=k_{2 a d}\left(q_{e}-q_{t}\right)^{2}
$$

where $k_{2 a d}$ expresses the rate constant (gr/mg.min). After being integrated and employing boundary values $(t=0$ to $t=t$ and $q_{t}=0$ to $q_{t}=q_{t}$ ), equation can be derived in the following $g^{35-38}$ :

$$
\frac{1}{q_{t}}=\frac{1}{k_{2 a d} q_{e}^{2}} \times \frac{1}{t}+\frac{1}{q_{e}}
$$

As shown in Eq. (10) if $t / q_{t}$ vs. $t$ is plotted, $k_{2 a d}$ and $q_{e}$ are defined through slope and intercept of the model. The intraparticle pattern which was presented by Weber and Morris is indicated as follows ${ }^{39,40}$ :

$$
q_{t}=k_{i} t^{0.5}+C
$$

where $k_{i}$ shows the rate constant $\left(\mathrm{mg} / \mathrm{g} \min ^{0.5}\right)$ and $C$ is a constant $(\mathrm{mg} / \mathrm{g})$. As shown in Eq. (11) if $q_{t}$ vs. $t^{0.5}$ is plotted, $k_{i}$ and $C$ can be specified through slope and intercept of the model, respectively. Tables 4 and 5 illustrates the constant parameters and $R^{2}$ values of models which are calculated by curve fitting of experimental data for MSU-S and $\mathrm{Al}_{2} \mathrm{O}_{3}-\mathrm{MSU}-\mathrm{S}$. As it is observed clearly, the best fitting for adsorption experimental data is the pseudo-second order pattern with maximum correlation coefficients in comparison with the intraparticle diffusion pattern and pseudo-first order models ${ }^{18,39,40}$. Figure 7 shows the performance of pseudo second order model to predict experimental data. Regarding the experimental and theoretical study, $k_{2}$, the pseudo-second order constant is related to the primary concentration of the adsorbate. From this model, it can be suggested that the adsorption procedure is in two-steps. The first stage exhibits the film diffusion from mixture to the outer surface of adsorbent and the second step indicates diffusion into the rough surface and abundant voids. One of the major advantages of this model is capability of modeling adsorption with significant change in adsorbate concentration which makes it reliable.

Fixed-bed adsorption/breakthrough test. Adsorption of DBT over $\mathrm{Al}_{2} \mathrm{O}_{3}-\mathrm{MSU}$-S. Figure 8 shows the breakthrough graphs of adsorption of DBT on $\mathrm{Al}_{2} \mathrm{O}_{3}-\mathrm{MSU}-\mathrm{S}$ at ambient temperature, atmospheric pressure and 


\begin{tabular}{|l|l|}
\hline Adsorbent & Adsorption capacities $(\mathbf{m m o l} / \mathbf{g})$ \\
\hline $\mathrm{MSU}-\mathrm{S}^{6}$ & 0.034 \\
\hline $\mathrm{CrO}_{2}$-MSU-S & 0.068 \\
\hline $\mathrm{Fe}_{2} \mathrm{O}_{3}-\mathrm{MSU}-\mathrm{S}^{6}$ & 0.047 \\
\hline $\mathrm{CeO}_{2}-\mathrm{MSU}-\mathrm{S}^{21}$ & 0.013 \\
\hline $\mathrm{Cu}_{2} \mathrm{O}-\mathrm{MSU}-\mathrm{S}^{21}$ & 0.038 \\
\hline $\mathrm{Al}_{2} \mathrm{O}_{3}$-MSU-S (present work) & 0.072 \\
\hline
\end{tabular}

Table 6. Adsorption capacity for DBT on different adsorbent.

1.0186 per hour LHSV. For these experiments $2.92 \mathrm{~g}$ of the model fuel/gram of sorbent ( $\mathrm{g}-\mathrm{F} / \mathrm{g}-\mathrm{A})$ was used in the fixed-bed adsorber. When saturation point is reached, the $C / C_{o}$ value for DBT rises strongly.

In order to find saturation capacity of $\mathrm{Al}_{2} \mathrm{O}_{3}-\mathrm{MSU}-\mathrm{S}$, integral calculus of the breakthrough curve is used. It was observed that adsorption load of presented sorbent to adsorb DBT from model fuel is $0.072 \mathrm{mmol} / \mathrm{g}^{7}$. Table 6 shows the adsorption capacity of different loads of metals on MSU-S adsorbent. It is obvious that the maximum adsorption load of DBT is related to $\mathrm{Al}_{2} \mathrm{O}_{3}$-MSU-S adsorbent.

\section{Conclusion}

In this work, MSU-S was synthesized, modified with aluminum and characterized to be applied in adsorptive desulfurization of model fuel. Modification of present MSU-S by the aluminum had negative effect which decreased the surface area for adsorption. Loading aluminum ions on the MSU-S enhanced adsorption selectivity through ion-exchange in the adsorbent. Comparing between aluminum modification and other metal modified MSU-S showed that capacity drastically varied by the order of $\mathrm{Al}_{2} \mathrm{O}_{3}>\mathrm{CrO}_{2}>\mathrm{Fe}_{2} \mathrm{O}_{3}>\mathrm{Cu}_{2} \mathrm{O}>\mathrm{CeO}_{2}$. Finally, it was found that Temkin and pseudo-second order models are the best models to define DBT adsorption on $\mathrm{Al}_{2} \mathrm{O}_{3}$-MSU-S equilibrium and kinetics phenomena.

Received: 20 January 2021; Accepted: 12 April 2021

Published online: 23 April 2021

\section{References}

1. Barbara, P., Rufino, M. N., Campos-Martin, J. M. \& Fierro, J. L. G. Towards near zero-sulfur liquid fuels: A perspective review. Catal. Sci Technol. 1, 22-23 (2011).

2. Mansouri, A., Khodadadi, A. A. \& Mortazavi, Y. Ultra-deep adsorptive desulfurization of a model diesel fuel on regenerable $\mathrm{Ni}-\mathrm{Cu} / \gamma-\mathrm{Al} 2 \mathrm{O} 3$ at low temperatures in absence of hydrogen. J. Hazard. Mater. 271, 120-130 (2014).

3. Song, C. \& Ma, X. New design approaches to ultra-clean diesel fuels by deep desulfurization and deep dearomatization. Appl. Catal. B Environ. 41, 207-238 (2003).

4. Wang, J., Hua, W., Yue, Y. \& Gao, Z. MSU-S mesoporous materials: An efficient catalyst for isomerization of a-pinene. Bioresour. Technol. 101, 7224-7230 (2010).

5. Velu, S., Ma, X. \& Song, C. Selective adsorption for removing sulfur from jet fuel over zeolite-based adsorbents. Ind. Eng. Chem. Res. 42, 5293-5304 (2003).

6. Ahmadi, M., Anvaripour, B., Khosravi-Nikou, M. R. \& Mohammadian, M. Selective denitrogenation of model fuel through iron and chromium modified microporous materials (MSU-S). J. Environ. Chem. Eng. 1, 1 (2017).

7. Kim, J. H., Ma, X., Zhou, A. \& Song, C. Ultra-deep desulfurization and denitrogenation of diesel fuel by selective adsorption over three different adsorbents: a study on adsorptive selectivity and mechanism. Catal. Today 111, 74-83 (2006).

8. Sentorun-Shalaby, C., Saha, S. K., Ma, X. \& Song, C. Mesoporous-molecular-sieve-supported nickel sorbents for adsorptive desulfurization of commercial ultra-low-sulfur diesel fuel. Appl. Catal. B Environ. 101, 718-726 (2011).

9. Van de Voorde, B. et al. N/S-heterocyclic contaminant removal from fuels by the mesoporous metal-organic framework MIL-100: The role of the metal ion. J. Am. Chem. Soc. 135, 9849-9856 (2013).

10. Ja’fari M, Ebrahimi SL, Khosravi-Nikou MR, ,. Ultrasound-assisted oxidative desulfurization and denitrogenation of liquid hydrocarbon fuels: A critical review. Ultrason. Sonochem. 40, 955-968 (2018).

11. Wang, Y., Yang, R. T. \& Heinzel, J. M. Desulfurization of jet fuel JP-5 light fraction by MCM-41 and SBA-15 supported cuprous oxide for fuel cell applications. Ind. Eng. Chem. Res. 48, 142-147 (2008).

12. Wang, L., Yang, R. T. \& Sun, C. Graphene and other carbon sorbents for selective adsorption of thiophene from liquid fuel. AIChE J. 59, 29-32 (2013).

13. Breysse, M. et al. Deep desulfurization: Reactions, catalysts and technological challenges. Catal. Today 84, 129-138 (2003).

14. Topsøe, H., Clausen, B. S., \& Massoth, F. E. Hydrotreating catalysis. Springer (1996).

15. Topsøe, H. Developments in operando studies and in situ characterization of heterogeneous catalysts. J. Catal. 216, 155-164 (2003).

16. Lei, Y., Shengqiang, W., Ruicong, W. \& Hongbing, Y. U. Selective removal of nitrogen-containing heterocyclic compounds from transportation diesel fuels with reactive adsorbent. Chin. J. Chem. Eng. 21, 558-563 (2013).

17. Zhang, Z. Y. et al. Adsorptive removal of aromatic organosulfur compounds over the modified Na-Y zeolites. Appl. Catal. B Environ. 82, 1-10 (2008).

18. Xue, M. et al. Selective adsorption of thiophene and 1-benzothiophene on metal-ion-exchanged zeolites in organic medium. J. Colloid Interface Sci. 285, 487-492 (2005).

19. Ahmadi, M., Mohammadian, M., Khosravi-Nikou, M. R. \& Baghban, A. Experimental, kinetic, and thermodynamic studies of adsorptive desulfurization and denitrogenation of model fuels using novel mesoporous materials. J. Hazard Mater. 1, 1 (2019).

20. Shahriar, S. A., Lin, H. \& Zheng, Y. Adsorptive denitrogenation and desulfurization of diesel fractions by mesoporous SBA15supported nickel (II) phosphide synthesized through a novel approach of urea matrix combustion. Ind. Eng. Chem. Res. 51, 14503-14510 (2012). 
21. Mohammadian, M., Khosravi-Nikou, M. R., Shariati, A. \& Aghajani, M. Model fuel desulfurization and denitrogenation using copper and cerium modified mesoporous material (MSU-S) through adsorption process. Clean. Technol. Environ. Policy 1, 1-18 (2018).

22. Rashidi, S., Nikou, M. R. K. \& Anvaripour, B. Adsorptive desulfurization and denitrogenation of model fuel using HPW and NiOHPW modified aluminosilicate mesostructures. Microporous Mesoporous Mater 211, 134-141 (2015).

23. Rashidi, H., Hamoule, T., Khosravi Nikou, M. R. \& Shariati, A. DME synthesis over MSU-S catalyst through methanol dehydration reaction. Iran J. Oil. Gas Sci. Technol. 2, 67-73 (2013).

24. Santos, A. L. et al. Silica-alumina impregnated with cerium, nickel, and molybdenum oxides for adsorption of sulfur and nitrogen compounds from diesel. Mater. Lett. 83, 158-160 (2012).

25. Munnik, P. et al. Copper nitrate redispersion to arrive at highly active silica-supported copper catalysts. J. Phys. Chem. C 115, 14698-14706 (2011)

26. Vantomme, A., Yuan, Z.-Y., Du, G. \& Su, B.-L. Surfactant-assisted large-scale preparation of crystalline $\mathrm{CeO}_{2}$ nanorods. Langmuir 21, 1132-1135 (2005)

27. Tan, P., Qin, J.-X., Liu, X.-Q., Yin, X.-Q. \& Sun, L.-B. Fabrication of magnetically responsive core-shell adsorbents for thiophene capture: $\mathrm{AgNO}_{3}$-functionalized $\mathrm{Fe}_{3} \mathrm{O}_{4} @$ mesoporous $\mathrm{SiO}_{2}$ microspheres. J. Mater. Chem. A 2, 4698-4705 (2014).

28. Rouquerol, J. et al. Recommendations for the characterization of porous solids (Technical Report). Pure Appl. Chem. 66, 1739-1758 (1994).

29. Hussain, A. H. M. S. \& Tatarchuk, B. J. Adsorptive desulfurization of jet and diesel fuels using $\mathrm{Ag} / \mathrm{TiOx}-\mathrm{Al}_{2} \mathrm{O}_{3}$ and $\mathrm{Ag} / \mathrm{TiOx}-\mathrm{SiO}_{2}$ adsorbents. Fuel 107, 465-473 (2013).

30. Meng, C., Fang, Y., Jin, L. \& Hu, H. Deep desulfurization of model gasoline by selective adsorption on Ag+/Al-MSU-S. Catal. Today 149, 138-142 (2010).

31. Lourenço, J. P., Fernandes, A., Henriques, C. \& Ribeiro, M. F. Al-containing MCM-41 type materials prepared by different synthesis methods: Hydrothermal stability and catalytic properties. Microporous Mesoporous Mater 94, 56-65 (2006).

32. Naik, S. P., Bui, V., Ryu, T., Miller, J. D. \& Zmierczak, W. Al-MCM-41 as methanol dehydration catalyst. Appl. Catal. A Gen. 381, $183-190$ (2010).

33. Mohammadian, M., Ahmadi, M. \& Khosravi-Nikou, M. R. Adsorptive desulfurization and denitrogenation of model fuel by mesoporous adsorbents (MSU-S and CoO-MSU-S). Pet. Sci. Technol. 35, 608-614 (2017).

34. Jeevanandam, P., Klabunde, K. J. \& Tetzler, S. H. Adsorption of thiophenes out of hydrocarbons using metal impregnated nanocrystalline aluminum oxide. Microporous Mesoporous Mater 79, 101-110 (2005).

35. Fouladgar, M., Beheshti, M. \& Sabzyan, H. Single and binary adsorption of nickel and copper from aqueous solutions by $\gamma$-alumina nanoparticles: Equilibrium and kinetic modeling. J. Mol. Liq. 211, 1060-1073 (2015).

36. Deravanesiyan, M., Beheshti, M. \& Malekpour, A. The removal of $\mathrm{Cr}$ (III) and Co (II) ions from aqueous solution by two mechanisms using a new sorbent (alumina nanoparticles immobilized zeolite)-Equilibrium, kinetic and thermodynamic studies. J. Mol. Liq. 209, 246-257 (2015).

37. Xu, X., Zhang, S., Li, P. \& Shen, Y. Equilibrium and kinetics of Jet-A fuel desulfurization by selective adsorption at room temperatures. Fuel 111, 172-179 (2013).

38. Wen, J., Han, X., Lin, H., Zheng, Y. \& Chu, W. A critical study on the adsorption of heterocyclic sulfur and nitrogen compounds by activated carbon: equilibrium, kinetics and thermodynamics. Chem. Eng. J. 164, 29-36 (2010).

39. Desta, M. B. Batch sorption experiments: Langmuir and Freundlich isotherm studies for the adsorption of textile metal ions onto Teff Straw (Eragrostis tef) agricultural waste. J. Thermodyn. 1, 1 (2013).

40. Fo, O. \& Odebunmi, E. O. Freundlich and Langmuir isotherms parameters for adsorption of methylene blue by activated carbon derived from agrowastes. Adv. Nat. Appl. Sci. 4, 281-288 (2010).

\section{Author contributions}

All the authors collaborated in data curation, methodology, software, formal analysis, and resources, writingreview and editing.

\section{Competing interests}

The authors declare no competing interests.

\section{Additional information}

Correspondence and requests for materials should be addressed to M.R.K.-N. or M.N.

Reprints and permissions information is available at www.nature.com/reprints.

Publisher's note Springer Nature remains neutral with regard to jurisdictional claims in published maps and institutional affiliations.

Open Access This article is licensed under a Creative Commons Attribution 4.0 International License, which permits use, sharing, adaptation, distribution and reproduction in any medium or format, as long as you give appropriate credit to the original author(s) and the source, provide a link to the Creative Commons licence, and indicate if changes were made. The images or other third party material in this article are included in the article's Creative Commons licence, unless indicated otherwise in a credit line to the material. If material is not included in the article's Creative Commons licence and your intended use is not permitted by statutory regulation or exceeds the permitted use, you will need to obtain permission directly from the copyright holder. To view a copy of this licence, visit http://creativecommons.org/licenses/by/4.0/.

(C) The Author(s) 2021 